\title{
correspondence
}

\section{Translating Chinese texts}

SIR,-Whilst preparing a written translation of taxonomic material from Chinese into English some time ago, I was struck by the great disparity between the highly specialised vocabulary of the subject and the simple nature of the grammar employed. This led me to wonder whether Chinese character data-handling techniques, with which I was then involved, might be applied to taxonomic texts to transform them relatively directly by machine into pidgin-English, adequate to convey the original data to the English-speaking reader, working in the appropriate scientific field. This approach seemed viable because Chinese in its written form is morphemic, each character conveying a quantum of meaning, and pidgin, which is itself primarily a direct transformation of Chinese sentences into English on a word-for-word basis, is a basic means of communication over parts of the Pacific Ocean.

An early stage of experiment, using a flowchart which was followed manually, showed that the original idea was promising, but the time-consuming nature of the work meant that relatively little material was processed. Later experiment, however, has involved actual machine processing of a number of texts, and the original ideas have been refined to accommodate some idiosyncrasies of Chinese word order, and to allow smoothing of the finished product. However, these improvements have been achieved without the need to use manual pre- or post-editing, the aim always having been to produce intelligible output by a routine operation which can be run by an operator whose only skill need be the identification of the Chinese characters in the original text.

The process which has been developed is not a linguistically-based general translation programme. It relies for its effectiveness on the careful selection of multi purpose glosses to represent multi-functional Chinese units in such a way that the reader's general knowledge of the field forces him into the correct choice of gloss for the context facing him. It is only in restricted areas, such as that found in taxonomic texts, that successful transformation can operate, and then it will only produce pidgin, however smoothed, rather than everyday English. However, I feel that the results so far indicate probable eventual success in providing a workable first sieve for the assessment of the large bulk of Chinese taxonomic data which at present seems to be largely unavailable to the Western scientist.

In spite of its inherent interest, it would be of little practical use to develop pidgin transformation further in the absence of any live demand for such a facility. If any readers feel that this type of transformation of taxonomic material would be of benefit to them, I would be grateful to hear from them. To give some idea of the form of output from the process, I append the result of one machine transformation, which shows the general style, and also illustrates how the multichoice glosses operate (see below).

\section{P. H. NANCARROW}

Faculty of Oriental Studies,

Sidgwick Avenue,

Cambridge, $\boldsymbol{U K}$

\section{Wind power for the UK}

SIR,- Some comments are necessary on Martin Ryle's article on 'Economics of alternative energy sources', (12 May, page 111). Whilst his suggestions on storage systems may be useful, his claim that wind power could be a substantial energy resource without much environmental impact is grossly exaggerated.

The coastal area of the UK is not $1.5 \times 10^{5} \mathrm{~km}^{2}$ as stated in the article; in fact the total land area of the $\mathrm{UK}^{1}$ is only $2.4 \times 10^{5} \mathrm{~km}^{2}$. To obtain an annual output of $0.56 \times 10^{9} \mathrm{GJ}$ at a mean density of $2.8 \mathrm{GJ} \mathrm{m}^{-2}$ from a swept area that is $4 \times 10^{-3}$ of the ground area (all figures quoted), one would need an area of $5 \times 10^{4} \mathrm{~km}^{2}$. Thus a fifth of the total area of the UK would have to be covered with towers about $60 \mathrm{~m}$ in height at distances apart of about $1 \mathrm{~km}$. It is questionable whether this is practicable. The costs of siting the aerogenerators over all types of country have not been estimated.

In any case the visual impact on the environment would be overwhelming, and in our windier more scenic areas the view would mainly consist of endless rows of towers stretching in every direction. Also the question of noise from the $1 \mathrm{MW}$ turbines, which will be only $1 \mathrm{~km}$ apart, is not mentioned.

A more practical upper limit on energy from wind power has been estimated by the Energy Technology Support Unit at Harwell to be the equivalent of about 8 million tons of coal a year from $10^{4}$ generators each of about $1 \mathrm{MW}$ rating ${ }^{2}$. Without an immense cost to the environment wind power could not make a substantial contribubtion to Britain's energy requirement.

\section{F. Clement}

Theoretical Physics Division,

AERE, Harwell, UK

1 The New Oxford Atlas (Oxford University Press, 1975).

2 Energy R\&D in the United Kingdom. A Discussion Document (1976).

\section{Trinucleus Murchiscin 1839.}

glabella $(e / I)$ a $11 /$ both (have) convex (front) lobe(s). (has/have) thrire pair(s) short a deep glabeli a (e/r)

frinye(s) upper lamella (e)'s small pit(s), irrespective of whether at/on anterior portion and/Or iateral portion(s) equally deep, distributed within the radial sulcus/i.

pygidium/al broad, breadth approximately is length's 3 cr 4 times.

genotype: rrinucleus fimbriatus Murchison.

period distributed: Asia and(also) Europe 